\title{
Hybrid Energy Harvester for Medical Sensor Node toward Real-Time Healthcare Monitoring
}

\author{
Saeed Mohsen ${ }^{*}$ \\ Faculty of Engineering, Ain Shams University, Cairo, Egypt \\ Received 14 January 2021; received in revised form 16 February 2021; accepted 04 March 2021 \\ DOI: https://doi.org/10.46604/peti.2021.7002
}

\begin{abstract}
In healthcare applications, the remote monitoring for moving patients depends on medical sensor nodes, which should be mobile. Thus, the power mains of medical sensor nodes should be disconnected most of the time to monitor natural movements of patients. In this paper, a self-sustainable medical sensor node is proposed for healthcare monitoring applications. The node implementation consists of a microcontroller unit (MCU), a photo-plethysmography (PPG) sensor, a Bluetooth low energy (BLE) module, and a MPU module that includes a gyroscope with accelerometer. The power supply of the node is a hybrid energy harvester developed to provide a sustainable energy for the sensor node. The harvester is composed of a photovoltaic (PV) panel, a thermoelectric generator (TEG) module, a DC-DC converter, and a super-capacitor. Experimental results illustrate that the proposed node can monitor a physiological data on a mobile device using the BLE Terminal application.
\end{abstract}

Keywords: medical sensor node, healthcare, energy harvesting, super-capacitor

\section{Introduction}

In the last decade, sensor nodes have played an effective role in biomedical fields [1-3]. However, the power supply of sensor nodes is frequently batteries, which have limited lifetime [4-5]. Energy harvesters can extend the battery lifetime ofsensor nodes [6-9]. Photovoltaic and thermoelectric energy harvesters are used for the reason that they have high power density [10]. Thus, a hybrid photovoltaic-thermoelectric energy harvester is implemented to overcome the limitation of using batteries.

There are multiple sensor nodes presented for medical applications [11-13]. Toh et al. [11] present an autonomous wearable sensor node with flexible photovoltaic energy harvesting. It utilizes an analog maximum power point tracking technique to manage the power of the node. Lim et al. [12] introduce a solar energy harvester for a sensor device. It includes a photovoltaic panel (PV), a DC-DC boost converter, and a battery. Tran and Chung [13] present an autonomous sensor node, which consists of a Photoplethysmogram (PPG) sensor and an Electrocardiogram (ECG) sensor, to monitor a patient's physiological data supplied by battery. The data of the sensor node is visualized by using the myMonitor Android application.

This paper presents an autonomous medical sensor node powered by a sustainable hybrid energy harvester. This harvester is developed based on a low-power DC-DC converter with two super-capacitors. These super-capacitors are used as backup power supply with overall capacity of $12.5 \mathrm{~F}$. The harvested hybrid energy is sufficient to supply the medical sensor node. The data of the sensor node is collected by PPG, gyroscope and accelerometer sensors. The data is transmitted to the BLE Terminal android application via BLE technology.

* Corresponding author. E-mail address: g17082131@eng.asu.edu.eg 
The reminder of the paper is organized as follows: Section 2 introduces the energy harvesting technology. Section 3 presents the development of the medical sensor node with the hybrid energy harvester. The experimental results are illustrated in section 4. Section 5 presents the conclusion of the paper.

\section{Energy Harvesting Technology}

Energy harvesting is a technology that converts and stores an energy from an environmental source for supplying autonomous devices [14]. The generic block diagram of energy harvesting technology is illustrated in Fig. 1. The block diagram consists of five blocks. The first one is environmental source, i.e. light, thermal, radio frequency (RF), vibration, wind, etc. Energy harvester is the second block, which converts an environmental energy into electrical energy. The third block refers to conversion and energy management, which is used to maximize the output power of the energy harvester. The fourth block is energy storage, which stores the harvested energy as backup. Energy storage can be rechargeable batteries or super-capacitors. There is a trade-off between them in terms of energy density and charging cycles. Super-capacitors have unlimited charging cycles in comparison with batteries, while the batteries have higher energy density than super-capacitors [15]. Finally, energy harvesting technology is employed to power a device, e.g. a medical sensor node.

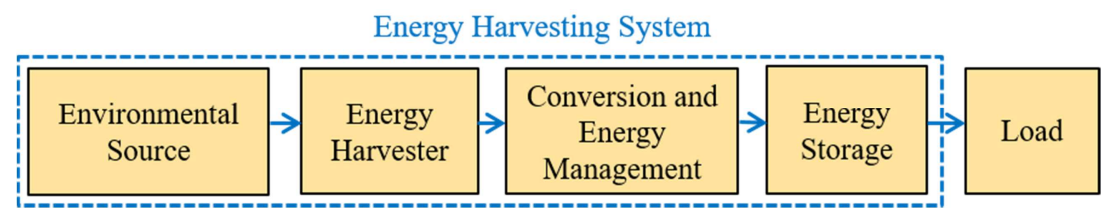

Fig. 1 The generic block diagram of energy harvesting technology

Table 1 shows power densities of different energy sources [16]. An outdoor light has a power density of $15 \mathrm{~mW} / \mathrm{cm}^{2}$, while the power density of an indoor light is $100 \mu \mathrm{W} / \mathrm{cm}^{2}$. Also, the power density from a thermal energy source is $60 \mu \mathrm{W} / \mathrm{cm}^{2}$, and the power density from a vibration energy source is $335 \mu \mathrm{W} / \mathrm{cm}^{2}$. In addition, the radio frequency (RF) can generate a power in the range of 0.1 to $1 \mu \mathrm{W} / \mathrm{cm}^{2}$. Finally, an air flow energy source has a power density of $7600 \mu \mathrm{W} / \mathrm{cm}^{2}$ at a velocity of $5 \mathrm{~m} / \mathrm{s}$. It is clear that the highest energy source is outdoor light. On the other hand, the thermal energy provides a convenient energy source with medical sensor nodes due to the fact that body heat is an inherent characteristic of human body. Therefore, the combination of light and thermal energy sources is used in the proposed system.

Table 1 Power densities of different energy sources

\begin{tabular}{|c|c|}
\hline Energy Source & Power Density $\left(\mu \mathrm{W} / \mathrm{cm}^{2}\right)$ \\
\hline Light (outdoors) & 15000 \\
\hline Light (indoors) & 100 \\
\hline Thermal & 60 \\
\hline Vibration & 335 \\
\hline Radio frequency (RF) & $0.1-1$ \\
\hline Air flow & $7600($ at $5 \mathrm{~m} / \mathrm{s})$ \\
\hline
\end{tabular}

\section{Development of Medical Sensor Node with Hybrid Energy Harvester}

\subsection{Architecture}

Fig. 2 demonstrates the proposed architecture of the medical sensor node with hybrid energy harvester. This architecture is composed of a PPG sensor to measure the heartbeats of a patient, a MPU module that include an accelerometer to sense the patient's linear accelerations and a gyroscope to detect the angular velocity, a BLE module that send the sensors data to a smartphone, and a microcontroller unit (MCU) that collect these sensors data for processing. This sensor node is powered by a hybrid energy harvester, which contains a thermoelectric generator (TEG) module to generate an electric power of the thermal energy of patient body, a PV panel to convert the light into an electric power, and a DC-DC converter to fix the voltage of PV panel and TEG module to charge a small-size super-capacitor. 


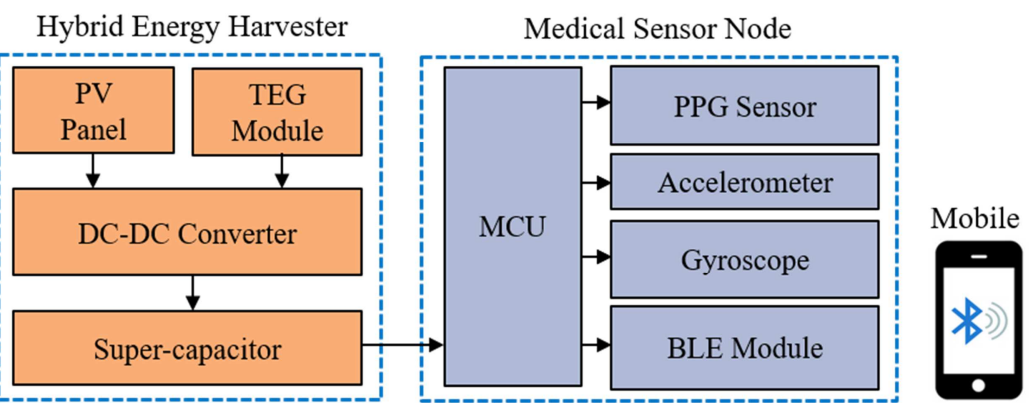

Fig. 2 The architecture of the medical sensor node with the hybrid energy harvester

\subsection{Hardware and software implementation}

The hardware implementation of the medical sensor node with hybrid energy harvester is shown in Fig. 3. It includes a flexible PV panel (MPT3.6-75) with an area of $7.2 \times 6.0 \mathrm{~cm}^{2}$ and a TEG module (SP1848-27145). It has a small-size of $4 \mathrm{~cm}$ $\times 4 \mathrm{~cm} \times 0.4 \mathrm{~cm}$. The PV panel and the TEG module are connected in parallel. The DC-DC converter is based on a LTC3105 chip from linear technology ${ }^{\circledR}$. This converter has high efficiency with input voltage from 0.2 to $5 \mathrm{~V}$. The energy storages are two super-capacitors (HV1625-2R7256R) that have capacity of $25 \mathrm{~F}$ and voltage rate of $2.7 \mathrm{~V}$. These super-capacitors are connected in series with voltage rate of $5.4 \mathrm{~V}$. The microcontroller unit (MCU) is a low-power AT mega-328p manufactured by Atmel. This unit has speed of $16 \mathrm{MHz}$ with operating voltage of $5 \mathrm{~V}$. The PPG sensor is selected SEN-11574. It is a high range from 0 to $200 \mathrm{bpm}$. The MPU module is chosen 6050 with accelerometer resolution in the range of -2 to $+2 \mathrm{~g}$. Its gyroscope angular velocity is between -250 to +250 degree/second [17]. The used BLE module is BT05 that has the range of 100 meters.

Fig. 4 describes the software flowchart of the medical sensor node. The sensor node is operating in two modes: active and sleep. Firstly, the microcontroller is configured in active mode. Secondly, it continuously measures the data of the sensors. Thirdly, the sensor data are sent for a duration of 3 seconds using the BLE module. Fourthly, the sensors are turned off. Fifthly, the BLE module is slept and then, the microcontroller enters in sleep mode for a period of 597 seconds to save the power consumption of the node. Finally, the previous steps are continuously repeated in a loop [18].

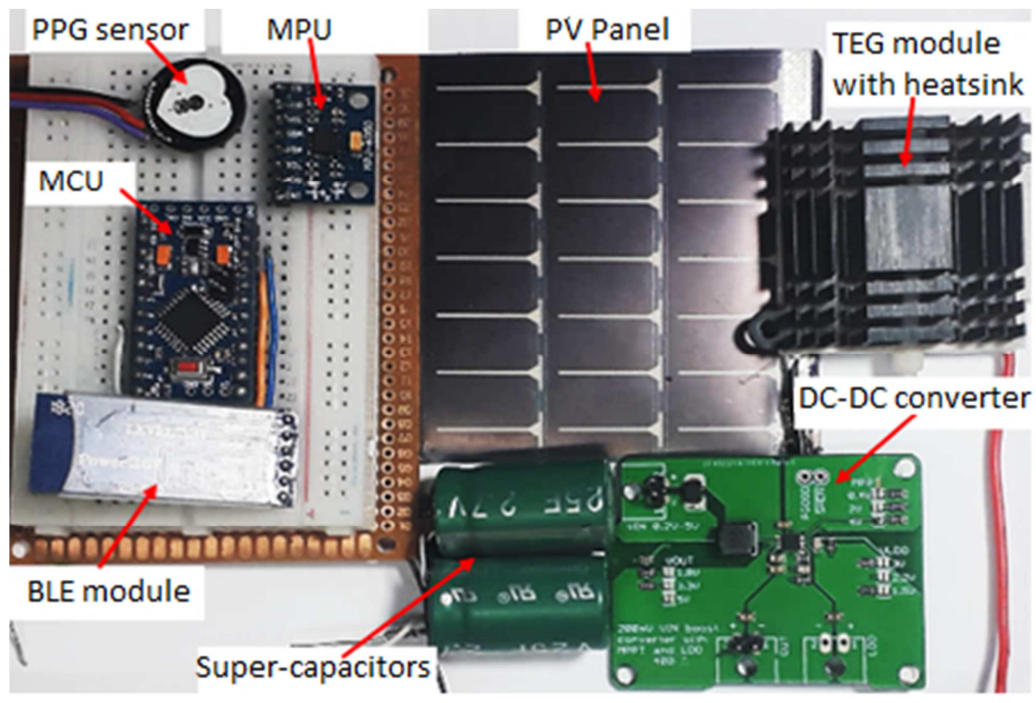

Fig. 3 Hardware implementation of the medical sensor node with the energy harvester

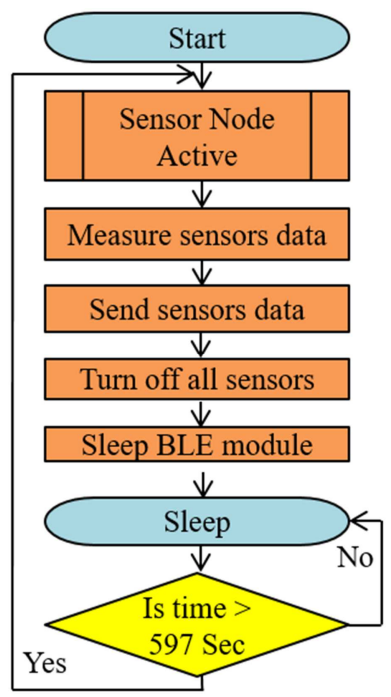

Fig. 4 Software flowchart of the medical sensor node

\section{Experimental Results}

Fig. 5 describes experimentally the I-V-P electrical characteristics of the PV panel under illumination of $1000 \mathrm{~W} / \mathrm{m}^{2}$. The orange and blue curves are the photovoltaic power $\left(P_{p v}\right)$ and current $\left(I_{p v}\right)$ respectively versus the photovoltaic voltage $\left(V_{p v}\right)$. The 


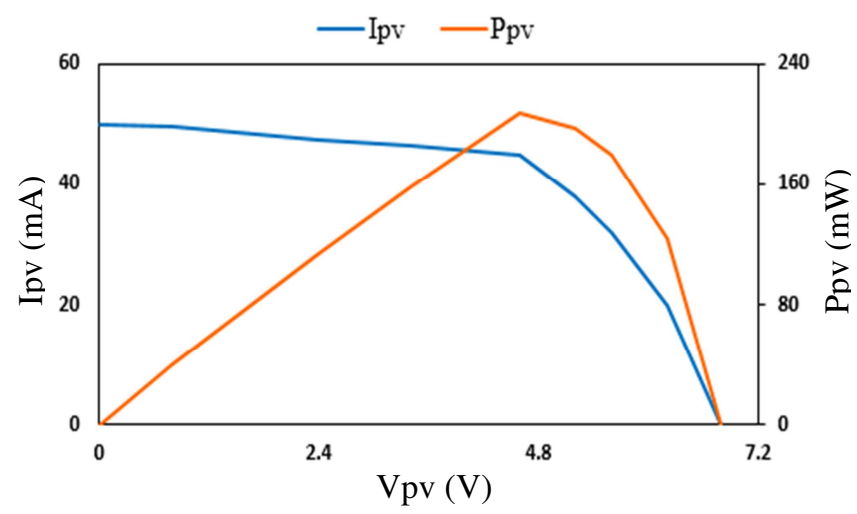

Fig. 5 I-V-P electrical characteristics of the PV panel at $1000 \mathrm{~W} / \mathrm{m}^{2}$

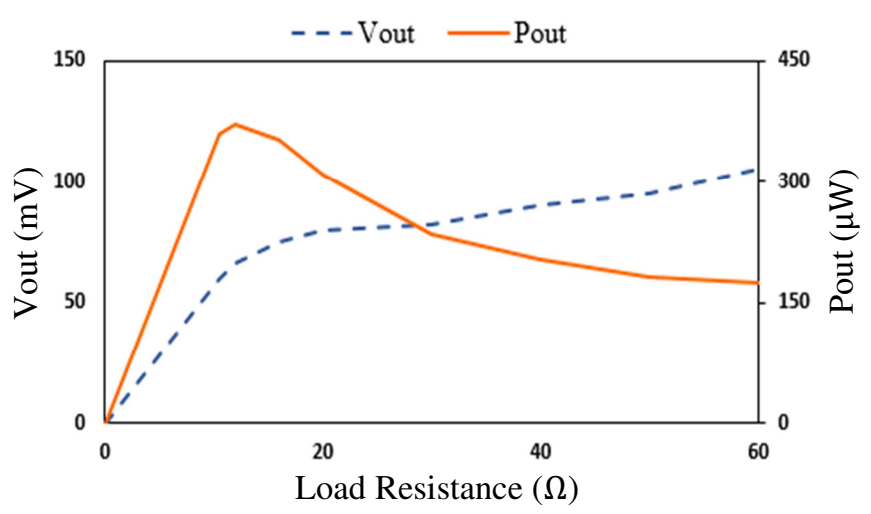

Fig. $6 \mathrm{R}-\mathrm{V}$ and R-P characteristic curves of the TEG at $\Delta T=5{ }^{\circ} \mathrm{C}$

maximum power reaches to $207 \mathrm{~mW}$ at voltage of 4.6V. Fig. 6 shows the R-V and R-P characteristic curves of the TEG module at $\Delta T=5^{\circ} \mathrm{C}$. The maximum output power $\left(P_{\text {out }}\right)$ is measured at $10.5 \Omega$ load resistance. Also, the dashed blue curve shows the maximum output voltage $\left(V_{\text {out }}\right)$ of $105 \mathrm{mV}$ with a $60 \Omega$ load resistance.

Fig. 7 shows the charging curve of the $12.5 \mathrm{~F}$ super-capacitor of the hybrid energy harvester. The voltage of the super-capacitor is increased from $2.6 \mathrm{~V}$ to $5 \mathrm{~V}$ in 165 minutes. Table 2 demonstrates the charging rate of the $12.5 \mathrm{~F}$ super-capacitor. The voltage measurements of the super-capacitor are taken via the EXCEL multi-meter. When the PV panel generates the power higher than the TEG module during the sunlight, the DC-DC boost converter starts to charge the super-capacitor. Under the darkness case, the TEG module supplies power to charge the super-capacitor.

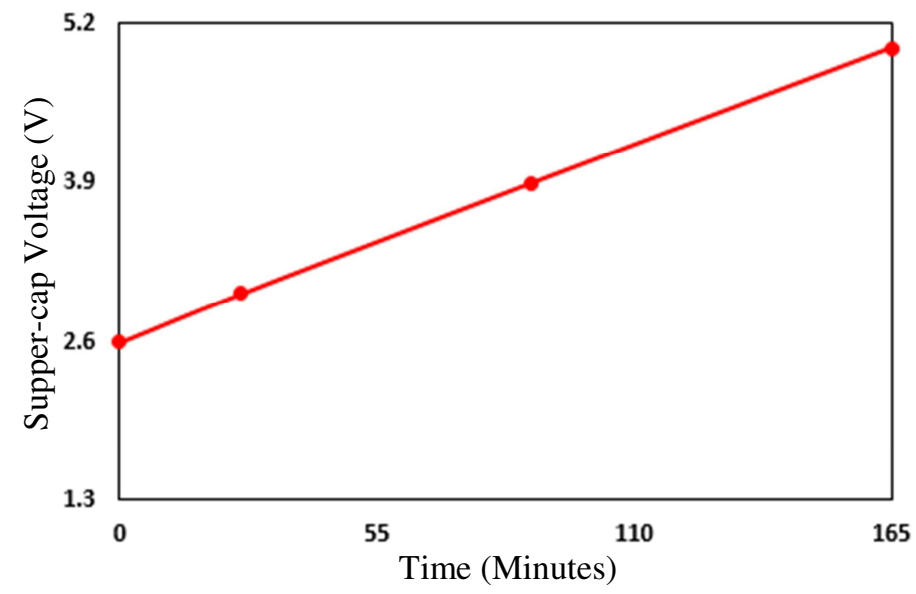

Fig. 7 Charging curve of the $12.5 \mathrm{~F}$ super-capacitor

Table 2 Charging rate of the $12.5 \mathrm{~F}$ super-capacitor

\begin{tabular}{|c|c|c|}
\hline Time Intervals (min) & Charging Rate $(\mathrm{mV} / \mathrm{s})$ & Voltage $(\mathrm{V})$ \\
\hline $0-26$ & 0.25 & $2.6-3.0$ \\
\hline $26-88$ & 0.24 & $3.0-3.9$ \\
\hline $88-165$ & 0.23 & $3.9-5.0$ \\
\hline
\end{tabular}

Table 3 Power consumption of the sensor node

\begin{tabular}{|c|c|c|c|}
\hline Mode & Current $(\mathrm{mA})$ & Time $(\mathrm{s})$ & Power $(\mathrm{mW})$ \\
\hline Active & 20 & 3 & 100 \\
\hline Sleep & 1.5 & 597 & 7.5 \\
\hline
\end{tabular}

Table 3 illustrates the measured power consumption of the sensor node for each mode. In active mode, the node consumes current of $50 \mathrm{~mA}$. Also, the measured current consumption in the sleep mode is $29 \mathrm{~mA}$. According to the flowchart of the node, the total period $(T)$ of the sensor node is 600 seconds (10 minutes) and the operating voltage of the sensor node is $5 \mathrm{~V}$. Hence, the average power consumption $\left(P_{\text {avg }}\right)$ of the sensor node is calculated using Eq. (1). Therefore, the average power consumption is equal to $7.96 \mathrm{~mW}$.

$$
\mathrm{P}_{\text {avg }}=\left(\mathrm{P}_{\text {Active }} \times \mathrm{T}_{\text {Active }}+\mathrm{P}_{\text {Sleep }} \times \mathrm{T}_{\text {Sleep }}\right) / \mathrm{T}
$$


Fig. 8 shows the PPG signal that is captured from a patient's finger in a sitting position. The PPG signal is filtered by a digital low pass filter and recorded by using the serial monitor program. During the experiment, the node samples the pulse oximeter sensor at a sampling frequency of $100 \mathrm{~Hz}$. It is continuously monitored for 3 seconds. Fig. 9 illustrates the monitored physiological data of the patient on the BLE Terminal android Application. In this figure, the reading of a heartbeat is monitored with $60 \mathrm{bpm}$ and is stored in a mobile phone for displaying. The readings of the patient's body acceleration are displayed with $-1 \mathrm{~g}$ in X, Y, and Z directions. Also, the readings of the angular velocity of the patient body are 180 degree/sec in $\mathrm{X}, \mathrm{Y}$ directions and 45 degree/sec in $\mathrm{Z}$ direction. Thereby, these physiological data are an indication of patient status. In other words, a doctor can detect the status via a transmitted data from the patient through the Bluetooth low energy (BLE) of the node to a mobile phone of the doctor.

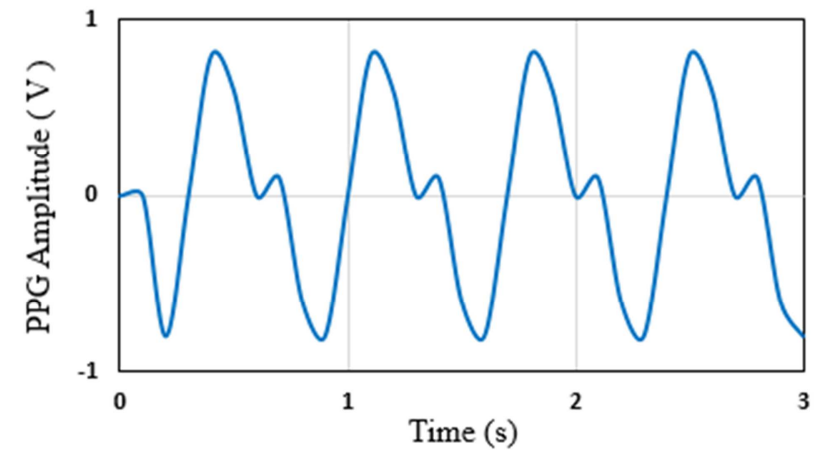

Fig. 8 The captured PPG signal from a patient's finger

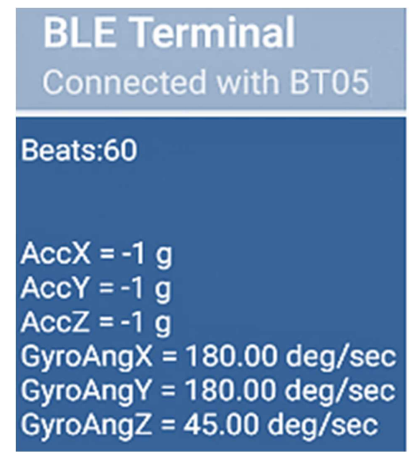

Fig. 9 Screen shot of the monitored physiological data

Finally, Table 4 illustrates a comparison between the proposed system and previous studies. In this work, the proposed sensor node has three physiological parameters, which are more than the nodes parameters in [11-13]. The Bluetooth low energy (BLE) wireless technology offers a higher range than the technologies in $[11,13]$. On the other hand, the utilized energy harvester in the proposed system is a combination of two energy sources, which are "flexible photovoltaic (PV) panel and thermoelectric generator (TEG)", while only one energy source "PV panel" was used in [11-13].

Table 4 Comparison between the proposed system and previous studies

\begin{tabular}{|c|c|c|c|c|}
\hline Reference & {$[11]$} & {$[12]$} & {$[13]$} & This Work \\
\hline Sensors & $\begin{array}{c}\text { Temperature } \\
\text { Sensor }\end{array}$ & $\begin{array}{c}\text { Temperature } \\
\text { Sensor }\end{array}$ & $\begin{array}{c}\text { PPG Senor and } \\
\text { ECG Senor }\end{array}$ & $\begin{array}{c}\text { PPG sensor and } \\
\text { MPU module }\end{array}$ \\
\hline $\begin{array}{c}\text { Number of } \\
\text { Physiological } \\
\text { Parameters }\end{array}$ & $\begin{array}{c}\text { One } \\
\text { (Temperature) }\end{array}$ & $\begin{array}{c}\text { One } \\
\text { (Temperature) }\end{array}$ & $\begin{array}{c}\text { Two } \\
\text { (PPG and ECG) }\end{array}$ & $\begin{array}{c}\text { Three } \\
\text { (Heartbeat, Acceleration, and } \\
\text { Angular Velocity) }\end{array}$ \\
\hline $\begin{array}{c}\text { Wireless } \\
\text { Technology }\end{array}$ & $\begin{array}{c}\text { RF Transceiver } \\
75 \mathrm{~m}\end{array}$ & $\begin{array}{c}\text { ZigBee } \\
100 \mathrm{~m}\end{array}$ & $\begin{array}{c}\text { HC-06 } \\
9 \mathrm{~m}\end{array}$ & $\begin{array}{c}\text { BLE } \\
100 \mathrm{~m}\end{array}$ \\
\hline Energy Harvester & PV Panel & PV Panel & PV Panel & $\begin{array}{c}\text { Flexible PV Panel } \\
\text { and TEG Module }\end{array}$ \\
\hline
\end{tabular}

\section{Conclusions}

This paper presents a self-sustainable medical sensor node for real-time healthcare monitoring. The node is powered by a hybrid energy harvester, which is a sustainable supply source during the running time of the node. The architecture of the harvester consists of a flexible photovoltaic panel to sense the irradiance of the sunlight with a thermoelectric generator (TEG) module to detect the temperature of human body. The flexible PV panel and TEG module are connected in parallel. The combination of the PV panel and TEG module are exploited to harvest the fast, sufficient, and more stable energy from the sunlight and the source of body heat. The proposed node continuously measures the heartbeats, accelerations and directions of a patient's body. Finally, a physiological data of the sensor node is monitored on the BLE Terminal android application. In the future, multiple medical sensor nodes will be developed for a wireless body area network implementation. 


\section{Conflicts of Interest}

The authors declare no conflict of interest.

\section{References}

[1] M. Magno, G. A. Salvatore, P. Jokic, and L. Benini, "Self-Sustainable Smart Ring for Long-Term Monitoring of Blood Oxygenation," IEEE Access, vol. 7, pp. 115400-115408, 2019.

[2] T. Wu, F. Wu, J. M. Redoute, and M. R. Yuce, "An Autonomous Wireless Body Area Network Implementation towards IoT Connected,” IEEE Access, vol. 5, pp. 11413-11422, 2017.

[3] S. Mohsen, A. Zekry, K. Youssef, and M. Abouelatta, “An Autonomous Wearable Sensor Node for Long-Term Healthcare Monitoring Powered by a Photovoltaic Energy Harvesting System," International Journal of Electronics and Telecommunications, vol. 66, no. 2, pp. 267-272, 2020.

[4] A. Dionisi, D. Marioli, E. Sardini, E. Sardini, and M. Serpelloni “Autonomous Wearable System for Vital Signs Measurement with Energy-Harvesting Module," IEEE Transactions on Instrumentation and Measurement, vol. 65, no. 6, pp. 1423-1434, June 2016.

[5] A. Decker, "Solar Energy Harvesting for Autonomous Field Devices," IET Wireless Sensor Systems, vol. 4, no. 1, pp. 1-8, March 2014.

[6] T. Wu, M. S. Arefin, J. M. Redouté, and M. R. Yuce, “A Solar Energy Harvester with an Improved MPPT Circuit for Wearable IoT Applications," Proceedings of the 11th EAI International Conference on Body Area Networks, December 2016, pp. 166-170.

[7] T. Wu, M. S. Arefin, D. Shmilovitz, J. M. Redoute, and M. R. Yuce, "A Flexible and Wearable Energy Harvester with an Efficient and Fast-converging Analog MPPT," IEEE Biomedical Circuits and Systems Conference (BioCAS), October 2016, pp. 336-339.

[8] S. Barker, D. Brennan, N. G. Wright, and A. B. Horsfall, "Piezoelectric-Powered Wireless Sensor System with Regenerative Transmit Mode,” IET Wireless Sensor Systems, vol. 1, no. 1, pp. 31-38, March 2011.

[9] R. Hamid and M. R. Yuce, “A Wearable Energy Harvester Unit Using Piezoelectric Electromagnetic Hybrid Technique," Sensors and Actuators A: Physical, vol. 257, pp. 198-207, April 2017.

[10] F. Wu, C. Rudiger, and M. R. Yuce, "Design and Field Test of an Autonomous IoT WSN Platform for Environmental Monitoring," 27th International Telecommunication Networks and Applications Conference (ITNAC), November 2017, pp. 1-6.

[11] W. Y. Toh, Y. K. Tan, W. S. Koh, and L. Siek, “Autonomous Wearable Sensor Nodes with Flexible Energy Harvesting,” IEEE Sensors Journal, vol. 14, no. 7, pp. 2299-2306, July 2014.

[12] L. J. Chien, M. Drieberg, P. Sebastian, and L. H. Hiung, “A Simple Solar Energy Harvester for Wireless Sensor Networks," 6th International Conference on Intelligent and Advanced Systems (ICIAS), August 2016, pp. 1-6.

[13] T. V. Tran and W. Y. Chung, "High- Efficient Energy Harvester with Flexible Solar Panel for a Wearable Sensor Device," IEEE Sensors Journal, vol. 16, no. 24, pp. 9021-9028, October 2016.

[14] K. V. Naveen and S. S. Manjunath, "A Reliable Ultracapacitor Based Solar Energy Harvesting System for Wireless Sensor Network Enabled Intelligent Buildings," 2nd International Conference on Intelligent Agent and Multi-Agent Systems (IAMA), September 2011, pp. 20-25.

[15] S. Mohsen, A. Zekry, K. Youssef, and M. Abouelatta, "A Self-Powered Wearable Wireless Sensor System Powered by a Hybrid Energy Harvester for Healthcare Applications,” Wireless Personal Communications, vol. 116, no. 4, pp. 3143-3164, September 2020.

[16] A. S. Weddell and M. Magno, "Energy Harvesting for Smart City Applications," International Symposium on Power Electronics, Electrical Drives, Automation and Motion, June 2018, pp. 111-117.

[17] J. K. Lee, K. Kim, and S. Lee, "Stretchable, Patch-Type, Wireless, 6-axis Inertial Measurement Unit for Mobile Health Monitoring," Proceedings of Engineering and Technology Innovation, vol. 14, pp. 16-21, January 2020.

[18] N. Aphiratsakun and S. Liwsakphaiboon, "Path Control iRobot Create2 Based Sensors," Proceedings of Engineering and Technology Innovation, vol. 16, pp. 45-51, August 2020. 